\title{
Higienismo e os primórdios do esporte: os casos do Acre e de Goiás
}

\author{
Hygienism and the Premiods of Sport: \\ The Cases of Acre and Goiás
}

\author{
Jean Carlo Ribeiro \\ Universidade Federal do Tocantins (UFTO), Palmas/Brasil \\ Doutorando em Estudos do Lazer, Universidade Federal de Minas Gerais
}

Joyce Nancy da Silva Corrêa

Universidade Federal de Minas Gerais (UFMG), Belo Horizonte/Brasil Mestranda em Estudos de Lazer, Universidade Federal de Minas Gerais joycedga@hotmail.com

\begin{abstract}
RESUmo: No início do século XX, o esporte se constituía como um novo hábito, símbolo da modernidade, mesmo na hinterlândia brasileira em estados como Goiás e Acre, naquele período regiões que ainda carregavam a marca do atraso e do isolamento. Manifestações esportivas seriam registradas a partir de 1907 (no Estado de Goiás) e de 1909 (no território do Acre), demonstrando que esses aspectos tipificados na história do interior do Brasil não impediriam que o esporte se concretizasse como uma prática moderna e que contribuiria simbolicamente no processo de transformação de hábitos e costumes sociais. Presentes também nesse processo eram as retóricas higienistas, eugênicas e nacionalistas, efeito de um novo modelo educacional.
\end{abstract}

Palavras-chave: Esporte; Higienismo; História; Acre; Goiás.

ABSTRACT: At the beginning of the twentieth century, sport became a new year, a symbol of modernity, even in the Brazilian hinterland in states such as Goiás and Acre, having occurred for some time in the era of delay and exit of the year. Manifestations of 1937 (in the State of Goiás) and of 1909 (in the territory of Acre), demonstrating that the aspects typified in the history of Brazil did not prevent the sport from materializing as a modern practice and that helps symbolically No process of transformation of habits and social customs. The processing chains could be more hygienic rhetorical, eugenic and nationalistic, with effect of a new educational model.

KEYwORDS: Sport; Hygienism; History; Acre; Goiás. 


\section{INTRODUÇÃO}

Logo nos anos iniciais do século XX, uma "febre" esportiva influenciaria hábitos e comportamentos moldados na ação e no movimento que rapidamente se tornariam símbolo de modernidade, influenciando um ativismo físico que caracterizaria o esporte como um elemento presente e de forte influência nos debates e transformações que ocorreriam nas esferas da saúde, da educação e dos divertimentos.

No Brasil, inicialmente manifestada em maiores centros urbanizados e próximos ao litoral, porta de entrada das novidades e modernidades europeias, essa movimentação esportiva não demoraria a adentrar sua hinterlândia. Em contato com estas práticas, comunidades à margem do eixo das grandes regiões metropolitanas, incorporariam também novos hábitos e necessidades oriundos da civilização esportiva ora em ideação.

Em lugares como o recém incorporado território do Acre $^{1}$ e o Estado de Goiás, que neste período carregavam o fardo simbólico do abandono, do isolamento, da invisibilidade e do atraso próprio da ruralidade do sertão brasileiro, as primeiras manifestações esportivas seriam registradas a partir de 1907 (no Estado de Goiás) e de 1909 (no território do Acre), demonstrando que esses aspectos tipificados na história da hinterlândia brasileira não impediriam que o esporte se concretizasse como uma prática moderna e que contribuiria simbolicamente para o processo de transformação de hábitos e costumes sociais.

No mesmo período, o esporte figuraria como um elemento importante no ideal de construção de uma nação sadia. Apoiado no princípio "mens sana in corpore sano", os sports emergiriam como possibilidade de desenvolvimento físico da nação e já contava, desde então, com o apoio de higienistas como um dever

\footnotetext{
${ }^{1}$ O Acre foi incorporado ao território brasileiro por meio do tratado de Petrópolis, assinado em 17 de novembro de 1903 pelo Barão do Rio Branco e Joaquim Francisco de Assis Brasil. Ver: KLEIN, Daniel. A borracha no Acre: economia, política e representações (1904-1945). Tese (Doutorado) Universidade de São Paulo, São Paulo, 2013; COSTA, Craveiro. A conquista do deserto ocidental. Rio Branco: Fundação Cultura/Ministério da Cultura, 1998.
} 
social de aperfeiçoamento do corpo humano, no combate a moléstias, doenças e "males sociais" como a preguiça e a inércia física. ${ }^{2}$

Essa associação, em alguma medida, legitimaria a prática de esportes entre os jovens das elites econômicas de lugares como Acre e Goiás, fazendo da prática esportiva um símbolo de uma nova cultura, fruto dos modernos hábitos almejados pela nova república. Neste sentido, este estudo tem por objetivo destacar as primeiras práticas esportivas registradas no Acre e em Goiás, entendendo o discurso higienista como um aspecto qualificador dessas práticas entre as elites locais.

\section{HIGIENISMO E CULTURA PHYSICA E ESPORTIVA}

Presente no cenário brasileiro desde o século XIX, o princípio higienista norteou a integração de exercícios físicos oriundos de ambientes militares ao sistema educacional, entendendo o consequente desenvolvimento físico dos alunos como um importante elemento para uma reforma social, associada ao desenvolvimento da nação e à promoção do progresso. ${ }^{3} 0$ espaço escolar já era percebido desde então como um local estratégico de desenvolvimento de ações que contribuiriam para essa mudança.

Ainda no Brasil império, em 17 de setembro de 1851, o decreto $\mathrm{n}^{\circ}$ 630, iniciaria a primeira reforma do ensino no município da corte que traria em seus termos as preocupações com o desenvolvimento físico do aluno. Em 17 de fevereiro de 1854 , por meio do decreto $\mathrm{n}^{\circ} 1.331$ " $\mathrm{A}$ ", a proposta seria regulamentada e teria como estratégia política promover a "civilização" da população. Avanços como a obrigatoriedade do ensino elementar e o princípio constitucional da gratuidade se contrapunham aos termos contidos no art. 69 do documento, que impedia de se matricularem e de frequentarem a escola "meninos que padecerem moléstias contagiosas", "os que não tiverem sido vacinados" e "os escravos". 4

A inclusão oficial dos "exercícios gymnasticos" no ensino primário e secundário das escolas públicas do Rio de Janeiro em 1854, mesmo que ainda não

\footnotetext{
${ }^{2}$ PEREIRA. Footballmania: uma história social do futebol no Rio de Janeiro (1902-1938), 2008.

${ }^{3}$ DIAS. Momentos iniciais da Educação Física em Goiás (1917-1929), p. 97.

${ }^{4}$ Decreto $n^{\circ} 1.331$ "A" de 17 de fevereiro de 1854. Coleção das leis do império do Brasil de 1854. Tomo XVII. Parte 2 ${ }^{\mathrm{a}}$. Secção 12 ${ }^{\mathrm{a}}$. Na Typographia nacional. Rio de janeiro, 1854, p. 59.
} 
figurando como uma matéria de cadeira, faria da reforma Couto Ferraz ${ }^{5}$ a iniciativa pioneira no Brasil de introdução de tais atividades em escolas, ratificando a influência médica na educação formal, na qual esses profissionais apresentavam soluções "científicas" para a efetivação de um modelo higiênico de educação escolar.

Esse modelo, influenciado principalmente pelas ideias higienistas do médico francês Michel Lévy, ${ }^{6}$ propunha um sistema de organização escolar que apontava preocupações com seis "coisas não naturais" que ocasionavam doenças, ${ }^{7}$ entre elas, a questão da inatividade corporal, combatida pela "gesta" que seria a prescrição de exercícios físicos. Assim, os médicos determinavam um conjunto de exercícios físicos que deveriam ser oferecidos nas escolas, afastando os alunos do ócio e da libido sexual (que deveria ser ao máximo retardada) e, consequentemente, contribuindo com a formação de uma geração forte, robusta e saudável. A preocupação com a formação integral do aluno se apoiaria em aspectos de ordem física, moral e intelectual, estabelecendo uma política social capaz de organizar e normalizar modos de agir em crianças a partir de sete anos de idade, ocupando o tempo destes e evitando a corrupção tanto do físico quanto da alma. ${ }^{8}$

À gesta caberia a garantia da integridade física e moral do aluno e, em função disso, os médicos recomendavam vários exercícios que eram prescritos de acordo com a idade e o sexo. Para as meninas, a forte relação com o papel social designado ao gênero feminino direcionava os exercícios ao estímulo da respiração, além da postura e elegância feminina, auxiliando na formação de futuras esposas

\footnotetext{
${ }^{5}$ Como Ministro do Império entre 1853-1855, Luiz Pedreira do Couto Ferraz (Barão em 1867 e Visconde do Bom Retiro a partir de 1872) foi o responsável pela proposta de regulamentação do ensino público e particular no município da corte em 1854. Em função disso, a legislação ficou conhecida como "Reforma Couto Ferraz".

${ }^{6}$ Médico higienista francês que viveu entre 1809 e 1872. Autor da obra Traité d'hygiène publiquet et privèe, publicada em quarta edição no ano de 1862. Essa obra influenciou o saber médico no Brasil no século XIX, sendo muito citada em teses defendidas nas faculdades de medicina do Rio de Janeiro e da Bahia que tratavam dos temas "Educação Physica" e "Higiene escolar". Mais informações em: GONDRA. Artes de civilizar: medicina, higiene e educação escolar na corte imperial. 2000. (Tese de doutorado em Educação). Faculdade de Educação, Universidade de São Paulo, São Paulo, 2000.

${ }^{7}$ Circumfusa (área indicada para o funcionamento da escola), Applicata (normas e hábitos de vestimenta que deveriam ser seguidos pelos alunos), Ingesta (tipo de alimentação que os alunos deveriam fazer uso), Gesta (prescrição de exercícios corporais direcionados aos alunos), Excreta (refere-se à excreção orgânica) e Percepta (responsável pela educação dos sentidos dos alunos). Ver: CASTRO. Escravas, prostitutas e médicos: normalizando modos de vida da corte do Rio de Janeiro, 2016, p. 120-121.

${ }^{8}$ CASTRO. Escravas, prostitutas e médicos, p. 121-123.
} 
aptas à procriação, objetivando o modelo ideal de mulher no período. Entre os meninos a prescrição de sports como carreira, natação e esgrima, além da ginástica e dos saltos, ajudariam o fortalecimento e o desenvolvimento de um novo país. ${ }^{9}$

As qualidades desenvolvidas por meio do exercício se apresentariam como um forte fator de diferenciação social, elegendo um modelo de homem que refletindo os padrões europeus, representaria uma classe e uma "raça 'superior" e deixaria para trás todos as mazelas e miasmas oriundos de um Brasil colonial e atrasado. A gesta também alimentava a moral, os bons costumes e os valores sociais, promovendo a civilidade, a organização e o sentimento patriótico. Esses argumentos "científicos" ajudariam as elites econômicas a superar resistências à gimnastica e aos sports, já que os padrões da sociedade imperial brasileira ainda associavam o exercício (ou qualquer esforço físico) ao trabalho escravo.

Em 1882, já na fase final do período imperial, Rui Barbosa ratificaria as noções higiênicas do exercício ao redigir, como parlamentar no município da corte, os pareceres de análise do decreto ํㅜ 7.247, de 19 de abril de 1879, que reformava o ensino primário e secundário no município da Corte e o ensino superior em todo o Império. Barbosa, membro da "Comissão de Instrução Pública”, nestes pareceres sugeriria a inclusão da ginástica nos programas escolares tanto para meninos quanto para as meninas em observância aos preceitos médicos da época, além da equiparação dos professores desta aos de outras disciplinas, entendendo a importância do desenvolvimento físico em conjunto com o intelectual. ${ }^{10}$

A elite médica higienista brasileira, que desde o período imperial vislumbraria uma estratégia bio-política ${ }^{11}$ de controle e dominação social, utilizaria as reformas educacionais e a inserção efetiva da ginástica e do exercício no cotidiano escolar como uma oportunidade de instaurar uma nova "cultura physica", capaz de colaborar no atendimento das prerrogativas da transformação social pretendida.

Todavia, por algum tempo, a efetividade dos argumentos presentes nessa legislação ainda ficaria restrita ao Rio de Janeiro e somente a partir da década de

\footnotetext{
${ }^{9}$ CASTRO. Escravas, prostitutas e médicos, p. 121-123.

${ }^{10}$ Ver: OLIVEIRA. O que é Educação Física, 1989.

11 Termo cunhado por Foucault em Microfísica do poder, p. 49.
} 
1920 que os estados começariam a realizar suas reformas educacionais com a presença de jogos e exercícios por meio da Educação Física (geralmente ainda nomeada de ginástica). Esse movimento reformador da Educação brasileira existente durante a primeira república demoraria algum tempo para atingir a hinterlândia brasileira, assim como veria moroso o amadurecimento de setores presentes no próprio sistema educacional.

Mesmo com esse relativo "atraso" das políticas educacionais, os ideais higiênicos presentes em diferentes setores da sociedade já influenciavam jovens oriundos de regiões da hinterlândia brasileira que eram enviados para completar seus estudos em maiores centros urbanos, em destaque, São Paulo e Rio de Janeiro. Esses rapazes, na maioria das vezes pouco atraídos pelos enfadonhos, monótonos e repetitivos exercícios físicos, viam nos jogos e competições esportivas o divertimento e o prazer que faltavam aos primeiros. A cultura física apregoada pelos ideais higiênicos encontrara nos sports uma recreação saudável, promovedora de vantagens ao aperfeiçoamento orgânico, indispensável ao desenvolvimento físico da nação.

\section{SPORTS: UM NOVO HÁBITO NA HINTERLÂNDIA BRASILEIRA}

As primeiras décadas do século XX demonstrariam a força do capitalismo mundial na sua expansão para as periferias e a consequente implantação dos novos modelos da cultura popular, seja em regiões da própria Europa, seja em países fora dela. No sertão brasileiro, é claro, não foi diferente. Estes processos no interior do Brasil, paulatinamente, se solidificariam em momento posterior não somente à Inglaterra moderna, mas também aos maiores centros urbanizados do país, fazendo referência principalmente à capital Rio de Janeiro. Isso se deu, certamente, em função de condições socioeconômicas e geográficas muito específicas, mas o esporte, não diferente de outras práticas e hábitos sociais, se apresentaria com muita evidência como um dos elementos constitutivos desse pacote de modernidade que não demorariam a ser percebidos na hinterlândia.

Os goianos não se abstiveram das transformações comportamentais oriundas dos modernos costumes recém-chegados. Redesenhados por características locais, 
de maneira até relativamente precoce, os sports se tornaram elementos importantes e fundamentais da sociabilidade goiana. Prova disso são os primeiros registros de jogos de futebol em Goiás, datados em 1907, fruto da organização de partidas por um grupo de estudantes do Lyceu de Goiaz, na então capital, cidade de Goiás. ${ }^{12}$ Neste período, em cidades como o Rio de Janeiro e São Paulo, a presença de imigrantes ingleses e o entusiasmo das elites locais com o novo sport bretão já teria feito do football uma prática conhecida e praticada. No Rio de Janeiro, no ano de 1906, já existiam mais de 30 clubes de futebol ${ }^{13}$ e as primeiras partidas já ocorriam tanto lá quanto em São Paulo, desde antes do final no século XIX.

Charles Miller entraria para a história como o pioneiro do futebol no Brasil e, a partir de 1895, como um grande incentivador da prática da modalidade em São Paulo. No Rio de Janeiro, o nome do jovem Oscar Cox constaria como o precursor desta prática na então capital federal. As histórias de Muller e Cox não coincidentemente se assemelham. Os dois, apesar de brasileiros, tinham ascendência britânica e eram filhos de uma elite que, ao enviar seus herdeiros para estudos na Europa, seguiam uma tendência na recém inaugurada república brasileira, de busca por uma nova cultura civilizatória. Além disso, ratificava-se nos anais da história esportiva brasileira o caráter elitista do surgimento de tais práticas. Apesar da existência de registros de jogos de futebol no Brasil anteriores a Muller e Cox, a confirmação histórica desse "pioneirismo" da introdução do futebol em suas cidades retrata o caráter excludente da história do próprio país. ${ }^{14}$

A historiografia do esporte goiano também registraria o seu pioneiro: Walter Sócrates do Nascimento. Apesar de ter nascido em Goiás, Walter, que era filho de pai capixaba e mãe goiana, morou em São Paulo até os 15 anos de idade, quando então veio residir na capital goiana. Em 1907 chegaria à cidade de Goiás após longa viajem que se iniciaria de trem no trecho São Paulo - Araguari-MG, e seria completada a cavalo pelos mais de 400 km restantes, já que, em 1907, nem as obras da estrada de ferro em Goiás haviam se iniciado. ${ }^{15}$

\footnotetext{
12 DIAS. Primórdios do futebol em Goiás, 1907-1936, p. 34.

13 PEREIRA. Footballmania, p. 54.

14 PEREIRA. Footballmania, p. 13.

${ }^{15}$ ALVES FILHO. Arquivos do futebol goiano, p. 26-27.
} 
Essa figura histórica está descrita no livro "Arquivos do futebol goiano", do jornalista João Batista Alves Filho, publicado no ano de 1982. Neste, Walter narraria ao autor que o seu interesse pelo futebol se iniciara em 1905, quando ainda morava em São Paulo. Após chegar a Goiás no final do segundo semestre de 1907, começou a preparar o local dos jogos no largo do chafariz. ${ }^{16} 0$ terreno íngreme e coberto por um cascalho fino era demarcado por riscos no chão, sendo as traves compostas por duas varas fincadas no chão. O campo de jogo não obedecia às dimensões impostas pelas regras do football, provavelmente adaptado ao reduzido número de jogadores (5 ou seis em cada equipe), que se predispunham à novidade. Os "treinos" aconteciam à tarde e sem dias fixos. ${ }^{17}$ Walter, ao que parece, buscava reproduzir improvisadamente aquilo que havia observado no período em que vivera na capital paulista, considerando que, em 1907, a prática do football já era uma cena comum naquela cidade em virtude da popularização do jogo.

A improvisação também era perceptível na descrição das vestimentas. Rapazes do início do século XX não usavam calções, considerados vestimentas infantis. Walter daria a entender que as primeiras partidas eram jogadas de calça comprida, e somente com o passar do tempo foram cortadas pouco abaixo dos joelhos, mantendo a obrigação do uso de cinto. 0 traje era composto também por meias, sapatos ou botinas e, posteriormente, chuteiras, para aqueles que conseguiam adquirir o "valioso" equipamento. Como adereço final, na cabeça se viam gorros, bonés ou lenços, sendo que estes últimos também poderiam vir amarrados ao pescoço. ${ }^{18}$

Já em 1908, com a chegada do também estudante vindo de São Paulo, Renato Marcondes de Lacerda, e a adesão de outros colegas, já conseguiriam formar dois teams que disputariam matchs com a "técnica “ $1,2,3$ e 5" (1 goalkeeper, 2 fullbacks - right e left -, 3 half backs - center, right e left - e 5 forwards - center, inside right e left e outside right e left). Em pouco tempo, o team

\footnotetext{
${ }^{16}$ Conjunto arquitetônico na cidade de Goiás, localizado na atual praça Brasil Caiado. Neste espaço se localiza o "Chafariz de Cauda da Boa Morte", construído em 1778 e que, atualmente, compõe um dos conjuntos históricos mais antigos e valiosos da cidade de Goiás.

${ }^{17}$ ALVES FILHO. Arquivos do futebol goiano, p. 27.

${ }^{18}$ ALVES FILHO. Arquivos do futebol goiano, p. 27.
} 
ganharia nome: Goyaz Football Club. Os goals passariam a ser de bambu e surgiria a figura de um árbitro para mediar as partidas (a princípio, protagonizada pelos dois mais "experientes", Walter e Renato). ${ }^{19}$

No ano seguinte, equipados com calções (até o joelho) e camisas diferentes, o terreno inapropriado do Largo do Chafariz foi substituído por outro no João Francisco, ${ }^{20}$ um campo de terra demarcado e com goals de sarrafo. Em 1911, Walter retornaria a São Paulo para cursar engenharia na Escola Politécnica. Outros colegas da equipe também sairiam de Goiás para estudar. 0 contato entre o grupo pioneiro de sportmen seria temporariamente interrompido. Walter voltaria a Goiás em 1918 e trabalharia como engenheiro civil na abertura da estrada que liga a antiga capital a Campinas (município que se transformaria em bairro de Goiânia). Permaneceria em Goiás até 1928, quando então retornaria definitivamente para São Paulo.

$\mathrm{O}$ contexto desse primeiro relato não foge a uma realidade exaustivamente descrita nos registros históricos do futebol brasileiro: a ideia de que o futebol nasce na elite, entre jovens de famílias abastadas que veriam no novo sport uma prática moderna e elegante, inacessível a pessoas que não tinham acesso aos padrões sociais e econômicos deste privilegiado grupo. Desse modo, resguardada as particularidades inerentes ao período e à região, Goiás também registraria na história o seu pioneiro do futebol, seu mito fundador.

Mas o pontapé inicial na antiga capital não seria o suficiente para uma disseminação da novidade na cidade. 0 fato de obter a primazia nos registros dos primeiros movimentos do futebol no estado não impediu a cidade de vivenciar um marasmo na segunda década do século XX em relação ao novo sport. A dependência em relação ao primeiro grupo de praticantes, talvez, tenha se configurado como uma circunstância que teria inibido a disseminação da novidade esportiva após seus passos iniciais. A tarefa de dar continuidade ao feito dos jovens sportmen da velha capital ficaria designada a outras regiões que já apresentavam

\footnotetext{
${ }^{19}$ ALVES FILHO. Arquivos do futebol goiano, p. 30.

${ }^{20}$ Campo aberto localizado no atual bairro do João Francisco. No início do século XX, o local era palco das "cavalhadas", manifestação religiosa que é parte da festa do Divino Espírito Santo, na cidade de Goiás. O campo do João Francisco foi ocupado de diversas formas até virar bairro da Cidade de Goiás, na segunda metade do século XX. Ver: BRITTO. Entre mascarados, mouros e cristãos: por uma memória topográfica das cavalhadas no Campo do João Francisco em Goiás, 2015.
} 
um maior dinamismo econômico e crescimento demográfico. Mesmo acanhado, o processo de urbanização de cidades do interior goiano seria um fator que facilitaria o crescimento contínuo da prática dos sports.

No Acre, assim como em Goiás, as primeiras atividades esportivas seriam registradas ao final da primeira década do século $\mathrm{XX}$, mas não coube ao football a primazia das primeiras notícias sobre o esporte no território acreano. A princípio, circulariam notícias de outros estados brasileiros e de países da Europa que trariam consigo vocabulários e representações referentes ao sport.

Em 1909, seriam noticiados eventos de práticas esportivas de tiro e de hipismo, com forte apoio das autoridades públicas. O surgimento de clubs esportivos e recreativos incentivariam também as corridas pedestres e de bicicleta. Somente a partir de 1914 é que o futebol ganharia o cenário esportivo acreano com a criação de dois clubes na cidade de Senna Madureira, o "Teem dos Onze" e o "Alto Purús Club", ambos compostos de valorosos moços "por seu largo treino em outras cidades do paiz onde viveram". ${ }^{21}$ Mas diferentemente de Goiás, a historiografia acreana não registraria nenhum pioneiro, não protagonizando uma figura especifica nos registros das primeiras práticas esportivas na região.

A capital Rio Branco, vivenciaria um crescimento do interesse por essa prática somente a partir de 1919 com a organização de equipes como o Rio Branco Foot-ball Club, o Acreano Sport Clube e o Team Militar, e de espaços específicos para os matchs, ${ }^{22}$ destacando-se a praça Rodrigues Alves e Tavares de Lyra, que teriam importante papel na difusão do esporte.

No ano de 1921 ocorreria o primeiro torneio de futebol, nomeado de "Torneio Inicio",23 composto por todos os times de Rio Branco, algo que se repetiria mais adiante, contando com a participação do Xapury Foot Ball Club, time da vizinha cidade de Xapury.

Fundamentais na construção da representação de um corpo vigoroso seriam as notas sobre a importância do exercício físico, como a que circularia no ano de 1919, dizendo ser recomendações de um professor da Universidade da

\footnotetext{
${ }^{21}$ Sport. O Alto Purus, p. 1.

${ }^{22}$ CORRÊA. Sports na terra dos rincões: Acre - 1909 a 1922, p. 24-45.

${ }^{23}$ Desportos. Folha do Acre. Rio Branco, 16 de junho de 1921, n. 364, p. 3.
} 
Pensilvânia que "[a] melhor cousa que pode fazer quem não se senti bem e quiser recuperar de pressa o vigor perdido é entregar-se ao pedestrianismo". ${ }^{24}$

Ainda a partir de 1919, o foot-ball ganharia o apreço de parte da população de Rio Branco com a formação de novos clubes, a organização de campeonatos, a criação de uma liga ${ }^{25}$ para organizar os torneios, além de colunas dedicadas exclusivamente a noticiar, descrever e incentivar a modalidade, sobretudo nas colunas do jornal Folha do Acre. 0 jogo bretão, além de um momento de diversão, era também um meio pelo qual os acreanos poderiam demonstrar seu patriotismo e ideais eugênicos, como demostra a notícia abaixo, publicada em jornal da capital em 1920:

Para o bem do sport da nossa terra, que traz comsigo o vigor e altivez de uma raça, fazemos destas colunnas um apêllo ao exm. Sr. dr. Cunha Vasconcellos, digno Prefeito[...] a Banda de Musica da Companhia Regional abrilhante o campo de desportos, afim de, por essa forma, ajudarem a levantar o sport, porta aberta ao enrijamento dos músculos abatidos da mocidade, por este clima que nos atrophia e enerva. 0 sport prepara cidadãos fortes, dá vigor e altivez! Ajuda-lo é ser bom brasileiro. Tudo pois pelo sport, para nossa grandeza, para a nossa força phisica e moral. ${ }^{26}$

Esse tipo de associação ajudaria a transformar os tímidos passos iniciais do esporte acreano do final da primeira década do século $\mathrm{XX}$, em uma intensa movimentação esportiva na década seguinte, transformando relações sociais, trazendo novos hábitos e concepções a uma elite econômica local.

Contudo, a partir do ano de 1923, o Acre começaria a sofrer mais severamente os impactos da crise econômica advinda da queda do preço da borracha, seu principal produto. ${ }^{27}$ Segundo uma crônica no jornal sobre a situação, tornava-se "patente e manifesta a indolência dos grêmios locaes, pois, a não ser tres partidas entre os mais fortes, não mais teve logar outra". ${ }^{28}$

\footnotetext{
${ }^{24}$ Como devemos andar. A Reforma. Villa Seabra, 02 de novembro de 1919, n. 78, p. 2.

${ }^{25}$ Desportos. Folha do Acre. Rio Branco, 21 de abril de 1921, n. 356, p. 3.

${ }^{26}$ Folha do Acre. Rio Branco, 20 de maio de 1920, n. 313, p. 2.

27 Ver KLEIN. A borracha no Acre: economia, politica e representações (1904-1945, 2013; COSTA. A conquista do deserto ocidental, 1998.

${ }^{28}$ Desportos. Folha do Acre, Rio Branco, 02 de novembro de 1922, n. 436, p. 3.
} 
Dessa forma, mudanças na sociedade infligiriam as organizações esportivas, como por exemplo, a evasão do território por parte de pessoas que participavam ativamente da vida esportiva da cidade. Além disso, a falta de recursos faria com que algumas instituições ficassem adormecidas por algum tempo e outras desaparecessem de vez.

Como consequência, modificar-se-iam espaços públicos e criar-se-iam espaços privados para o desenvolvimento de práticas esportivas, notadamente o futebol. Mas, diferentemente de Goiás, que sustentaria um contínuo crescimento da prática dos sports no estado durante a década de 1920, o Acre, em meados de 1923, viveria um declínio da vivência de tais práticas.

\section{CONCLUSÃo}

Nos cenários regionais citados, semelhanças e disparidades são percebidas. Ao mesmo tempo que se aproximam historicamente em algumas características, tais como, datas e períodos, a forte presença de imigrantes e o destacado papel das cidades do interior no avanço esportivo nos dois estados, notadamente, manifestamse particularidades próprias de cada um, fruto de hábitos, costumes e condições préestabelecidas para o surgimento e o desenvolvimento da prática de esportes.

Os contextos regionais citados, de certa forma, remetem a uma imagem bastante diferente daquela que tão caracteristicamente afeta essas regiões, geralmente associada à ruralidade, ao isolamento e ao atraso cultural. As peculiaridades inerentes a cada um desses espaços regionais, além de enriquecerem sensivelmente a história local, formariam uma complexa rede, fundamental na composição da história esportiva brasileira, contribuindo efetivamente para uma "difusão reversa", ${ }^{29}$ conceito que contesta o entendimento simplificado das diferentes formas com que os esportes foram difundidos de um grupo para outro.

${ }^{29}$ Conceito desenvolvido por Maarten van Bottenburg. Ver em: BOTTENBURG. Além da difusão: o esporte e sua reconstrução em contextos transculturais, p. 12. 
A tradicional percepção da relação entre centros e periferias, grupos dominantes e dominados, que desconsidera processos de adaptação e reinterpretação, assim como de contestação e rejeição de manifestações esportivas, não contempla diferentes efeitos desses sistemas, rejeitando consequências que, necessariamente, devem ser analisadas e interpretadas.

Para lugares como Acre e Goiás do início do século XX, os sports chegariam, para além de uma proposta de divertimento, como uma reconfiguração de hábitos sociais que poderiam contribuir efetivamente na modernização e no desenvolvimento das cidades e da região. Tais práticas, reforçadas pelo ideal higienista como um forte potencial construtivo para uma nação grande, vigorosa e altiva, em tese, contribuiria para "incluir" definitivamente esses locais no "mapa" brasileiro.

As elites locais, projetando aquilo que imaginavam ainda faltar para serem incluídas na proposta de ressignificação social almejada pelo Brasil recém saído da República Velha, veriam nos sports uma prática qualificada para tal fim. Para eles, esse novo espaço social reconfigurado pelos valores higiênicos de saúde e beleza seria o palco idealizado para a "regeneração humana" em voga naquele momento histórico.

De fato, os sports inicialmente contribuiriam para esses processos, mas as dificuldades enfrentadas pelas elites locais fariam com que o desenvolvimento esportivo nessas regiões ocorresse em momento posterior a esses primeiros impulsos, quando tais práticas se popularizassem, escapando do domínio e da exclusividade destes primeiros.

\section{REFERÊNCIAS}

ALVES FILHO, J. B. Arquivos do futebol goiano. Goiânia: Gráfica O Popular, 1982. BOTTENBURG, Maarten van. Além da difusão: o esporte e sua reconstrução em contextos transculturais. Recorde, Rio de Janeiro, v. 9, n. 1, p. 1-18, jan./jun. 2016. 
BRITTO, C. C. Entre mascarados, mouros e cristãos: por uma memória topográfica das cavalhadas no Campo do João Francisco em Goiás. In: BRITTO, C. C.; PRADO, P. B. do; ROSA, R. L. Os sentidos da devoção: O Império do Divino na Cidade de Goiás (séculos XIX e XX). Goiânia: Editora Espaço Acadêmico, 2015.

CASTRO, M. R. de. Escravas, prostitutas e médicos: normalizando modos de vida da corte do Rio de Janeiro. Campo Grande: Ed. UFMS, 2016.

CORRÊA, Joyce. Sports na terra dos rincões: Acre - 1909 a 1922. Rev. Brasileira de Estudos do Lazer, v. 4, n. 3, p. 24-45, set.-dez., 2017.

COSTA, Craveiro. A conquista do deserto ocidental. Rio Branco: Fundação Cultura/Ministério da Cultura, 1998.

DIAS, C. Momentos iniciais da Educação Física em Goiás (1917-1929). Revista Brasileira de Educação Física e Esporte, 28 (1): 95-111, jan.-mar., São Paulo, 2014.

FOUCAULT, Michel. Microfísica do poder. Rio de Janeiro: Graal, 1979, p. 49.

GONDRA, J. G. Artes de civilizar: medicina, higiene e educação escolar na corte imperial. (Tese de doutorado em Educação). Faculdade de Educação, Universidade de São Paulo, São Paulo, 2000.

KLEIN, Daniel. A borracha no Acre: economia, política e representações (1904-1945). Tese (Doutorado). Universidade de São Paulo, São Paulo, 2013.

OLIVEIRA, M. V. de. O que é Educação Física. São Paulo. Brasiliense. 1989.

PEREIRA, L. A. de M. Footballmania: uma história social do futebol no Rio de Janeiro (1902-1938). Tese (doutorado). Departamento de História do Instituto de Filosofia e Ciências Humanas, Universidade Estadual de Campinas, 2008.

Sport. O Alto Purus. Senna Madureira, 16 de dezembro de 1917, n. 053, p. 1.

Desportos. Folha do Acre. Rio Branco, 16 de junho de 1921, n. 364, p. 3.

Como devemos andar. A Reforma. Villa Seabra, 02 de novembro de 1919, n. 78, p. 2.

Desportos. Folha do Acre. Rio Branco, 21 de abril de 1921, n. 356, p. 3.

Folha do Acre. Rio Branco, 20 de maio de 1920, n. 313, p. 2.

Desportos. Folha do Acre, Rio Branco, 02 de novembro de 1922, n. 436, p. 3.

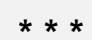

Recebido para publicação em: 25 jun. 2018.

Aprovado em: 27 nov. 2018. 